\title{
CallegeNews
}

\section{MEETING ANNOUCEMENT}

\section{American College of Medical Genetics 2005 Annual Clinical Genetics Meeting March 17-20, 2005 Gaylord Texan Resort \& Convention Center, Dallas, Texas}

\section{Dear Colleague,}

It is with great pleasure and excitement that we invite you to participate in the American College of Medical Genetics 2005 Annual Clinical Genetics Meeting, to be held March 17-20 at the Gaylord Texan Resort and Convention Center in Grapevine, Texas, just outside Dallas.

The 2003 and 2004 Annual Clinical Genetics Meetings were enormously successful. Professional attendance and the number of exhibitors increased nearly $60 \%$ over prior years, the number of contributed papers doubled, and both exhibits and sessions were rated very highly. The 2003 and 2004 conferences set the tone for the continued growth and success of the ACMG meeting!

The 2005 Annual Clinical Genetics Meeting will offer four days of superb educational opportunities, ranging from plenary and concurrent sessions and platform presentations to poster sessions, exhibits and Exhibitor Laboratory Theaters. A second session of platform presentations from submitted abstracts has again been added, nearly doubling the number of talks by attendees. Exhibitor Laboratory Theaters will again offer half hour stand-alone presentations showcasing the latest products, services and developments coming from industry. The first Industry-Sponsored Symposium was offered in 2004 and attracted over 200 attendees. We hope to offer more such symposia in 2005, providing increased learning opportunities in 90-minute breakfast sessions on Thursday, Friday and Saturday mornings. From the cutting-edge clinical and research presentations to the latest products and services in the exhibit hall and the opportunities to network with colleagues, the 2005 meeting can't be missed!

Our meeting site in 2005 is a new one for ACMG. Just minutes from the Dallas/Ft.Worth airport and nestled on a penin- sula along picturesque Lake Grapevine, the magnificent new Gaylord Texan is pure Texas in décor and style. Room rates for ACMG participants will be lower than the 2004 rates, only $\$ 185$ single/double, plus tax, and there will not be a resort fee. As a guest of the resort, you'll experience the best of the Lone Star State under the signature glass atrium where you can dine, shop, socialize, and be entertained among four-and-a-half acres of lush indoor gardens. Furthermore, within a short walking distance from the hotel, you can shop at the Grapevine Mills Mall and dine in a multitude of settings from local favorites to international fare. You will find family restaurants, an historic inn, themed restaurants and outdoor cafés.

Once again, contributed papers will be accepted electronically. The deadline for receipt of on-line submissions is December 10, 2004. Detailed instructions regarding the submission of abstracts are located at the ACMG website (www.acmg.net).

We are confident that the 2005 Annual Clinical Genetics Meeting will be highly relevant to your practice and will be a truly memorable meeting. Be sure to visit our website (www.acmg.net) on a regular basis for the latest updates on the meeting, ranging from educational offerings to the list of exhibiting companies.

We look forward to seeing you next March!

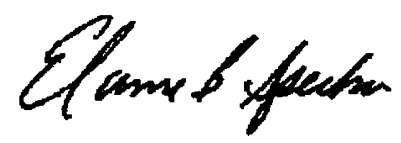

Elaine B. Spector, PhD, FACMG

2005 Program Committee Chair

University of Colorado Health Sciences Center

Denver, Colorado

\section{Chanles 9 . Es tem}

Charles J. Epstein, MD, FACMG

President 2003-2005

University of California School of Medicine

San Francisco, California 


\section{MILO GLADSTEIN FOUNDATION FOR BLOOM SYNDROME}

A new foundation to support research in Bloom syndrome has been established in Los Angeles by Richard and Laurie Gladstein. The foundation is named after their $31 / 2$ year-old son who is affected by this disorder. The founders express the wish that research supported by the foundation should aim at developing a therapy for Bloom syndrome or preventing its complications. Investigators who might be able to contribute towards this goal are invited to submit a letter of intent.

This letter of intent should contain the following information:
- Name, address and academic affiliation of the potential applicant

- Two page NIH style Bio-bibliography form

- A brief outline of the investigation to be initiated (not to exceed 2 pages).

- An outline of current resources and support

The letter-of-intent should be e-mailed to Richard Gladstein (rng@filmcolony.com). It will be evaluated by Drs. David L. Rimoin, James L. German, and Eberhard Passarge. After appropriate consultation a decision will be reached whether the applicant will be invited to submit a formal NIH style research application. This application will be evaluated by additional experts. 


\section{ACMG Genetics Reyiew Course JUNE 3-5, 2005}

Hyatt Regency O'HARe • ROSEmont, ILlinois

Dear Colleague:

As chairpersons of the upcoming ACMG 2005 Genetics Review Course we are pleased to invite you to attend the two-and-one-half day course to be held Friday-Sunday, June 3-5, 2005, at the Hyatt Regency O'Hare in Rosemont, Illinois. The course is designed to address clinical and counseling issues in medical genetics and should serve as a solid review in the basics of medical genetics as well as preparation for the upcoming examinations in general, counseling, laboratory and clinical aspects of genetics.

The Baylor College of Medicine Genetics Board Review Course was initiated in 1990 under the leadership of Dr. Arthur L. Beaudet. The ACMG Genetics Review Course became the successor to the Baylor course in 1999 and has remained the premier medical genetics review course. The ACMG is pleased to present this comprehensive course for the third time. The format will be similar to that of the Baylor course, including the use of sample examination questions.

This course will provide an overview of medical genetics with emphasis on current issues. Areas covered will include prenatal genetics, genetic screening, quantitative genetics, genetic syndromes and malformations, biochemical genetics, cancer genetics, basic cytogenetics, chromosomal syndromes, genetics of common disorders and molecular genetics. There will be lectures on the major areas of medical genetics by recognized experts in those fields. The lectures will be reinforced by a syllabus specifically designed to complement the material covered.

Participants will take a pre-review examination composed of questions similar to those one might encounter in board examinations. These will be graded and the answers to these and other practice questions discussed in workshops that will emphasize problem-solving and faculty/attendee interaction.

We urge you to register for the course starting January 2005. Space may be limited and registrations will be accepted on a firstcome, first-served basis. Look for further information on www.acmg.net early next year.<smiles>CC(C)(C)CCCCCCCCC1CC1</smiles>

Bruce R. Korf, MD, PhD University of Alabama Birmingham, AL

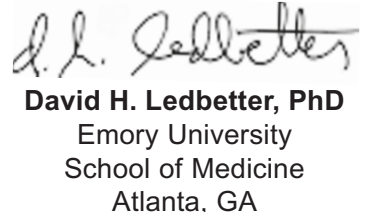

Atlanta, GA

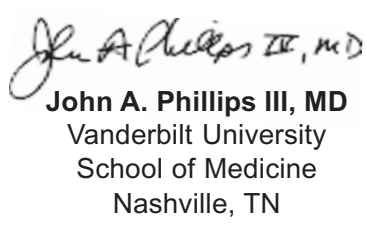

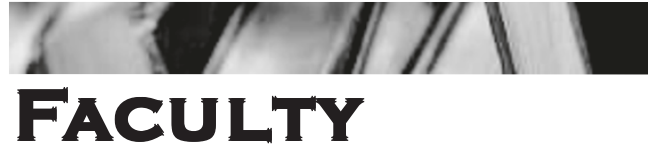

Bruce R. Korf, MD, PhD, FACMG

University of Alabama

Birmingham, AL

\section{David H. Ledbetter, PhD, FACMG}

Emory University School of Medicine

Atlanta, GA

\section{Carole Ober, PhD, FACMG \\ University of Chicago \\ Chicago, IL}

John A. Phillips III, MD, FACMG

Vanderbilt University School of Medicine

Nashville, TN

\section{Sharon E. Plon, MD, PhD, FACMG}

Baylor College of Medicine

Houston, TX

\author{
Nathaniel H. Robin, MD, FACMG \\ University of Alabama \\ Birmingham, AL
}

\section{David Valle, MD, FACMG}

Johns Hopkins University School of Medicine Baltimore, MD

\section{Ann P. Walker, MA, CGC}

University of California at Irvine Medical Center Irvine, CA

Louise E. Wilkins-Haug, MD, PhD, FACMG

Brigham \& Women's Hospital

Boston, MA

Before their talks, all faculty will disclose the existence of any financial interest and/or

other relationship(s) they might have with the

manufacturer(s) or provider(s) of any

commercial product(s) or service(s) to be

discussed during their presentations:

honorarium/expenses, grants or research

support, employee, a consultant role,

speakers' bureau member, stock ownership,

or any other special relationships. When

unlabeled uses are discussed, these will also

be indicated. 


\section{GoAls AND OBJectives}

Upon completion of this Course, participants should be able to:

Identify common genetic syndromes and discuss their clinical features

- Interpret standard molecular data and explain how to communicate results to families

- Perform simple quantitative genetic calculations and solve related problems

- Understand basic cytogenetics and identify features of common chromosomal disorders

- Recognize clinical features of selected metabolic disorders, describe their molecular basis and review how to provide counseling about them

Appreciate the extents and limits of prenatal tests and explain how to perform routine prenatal counseling

- Understand clinical and molecular aspects of inherited cancer syndromes and know how to provide counseling for common human cancers

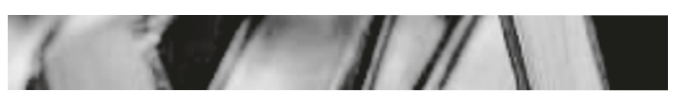

\section{REGISTRATION}

Detailed announcements will be mailed this autumn to members of the ACMG and NSGC, and to all individuals currently enrolled in training programs accredited by the $\mathrm{ABMG}$ or the ABGC. Online registration will open early in 2005 at the ACMG website:

www. acmg.net. Others may download the form from the ACMG web site on or about January 1, 2005.

The registration fee includes meals and the syllabus. ACMG members receive reduced registration fees! To apply for membership to the College, go to http://www.acmg.net/members/application.asp or contact Lori J. Oxendine. Completed membership applications must be received prior to registration in order to receive the membership discount.

\section{ACMG member registration}

Nonmember registration
$\$ 525$ advance $\$ 600$ on site

\$675 advance \$725 on site

\section{ACCREDITATION}

\section{STATEMENT}

The American College of Medical Genetics is accredited by the Accreditation Council for Continuing Medical Education to provide continuing medical education for physicians. The American College of Medical Genetics takes responsibility for the content, quality and scientific integrity of this CME activity. The ACMG designates this educational activity for a maximum of 20.25 hours in Category I credit toward the AMA Physician's Recognition Award. Each physician should claim only those hours of credit that he/she actually spends in the educational activity.

ACMG has applied for 20.25 hours of CEU credit for this course.

\section{hotel Reservations}

The Hyatt Regency O'Hare is the venue for the Course (located less than 5 miles from Chicago's O'Hare International Airport) and offers complimentary shuttle service to and from the airport.

Hotel reservations are the responsibility of the individual registrant. You may make your room reservations beginning the first week of January 2005. Rooms for the Course will be $\$ 149$ single/double. The Hyatt Regency O'Hare is accessible to persons with disabilities.

\section{CONTACT}

\section{INFORMATION}

For more information regarding the course or membership, please contact:

Lori J. Oxendine, Executive Assistant American College of Medical Genetics 9650 Rockville Pike

Bethesda, Maryland 20814-3998

Phone (301) 634-7127

Fax (301) 634-7275

Email: loxendine@acmg.net 